\title{
PENGAMATAN SKILL MOTORIK DAN FISIK DALAM UPAYA MENJADIKAN SOSOK MANUSIA BERKUALITAS
}

\author{
Oleh: Panggung Sutapa \\ Dosen IKORA FIK UNY
}

\begin{abstract}
Abstrak
Pengamatan skill motorik dan fisik yang dilakukan secara rutin dapat menemukan ada tidaknya keabnormalan perkembangan penginderaan, kreasi gerak, dan improvisasi gerak serta bentuk maupun sikap tubuh. Keberhasilan pengamatan perkembangan skillmotorik dan fisik sangat ditentukan oleh keahlian testor terutama dalam mempersiapkan unsur-unsur bentuk tes skill motorik maupun fisik.
\end{abstract}

Pengamatan kedua unsur tersebut dapat dilakukan dengan berbagai macam cara pengamatan skill motorik dengan melihat penguasaan ketrampilannya dalam grafik tingkat keberhasilan dan kegagalan untuk setiap tugas. Pengamatan aspek fisik dengan melihat pada posisi duduk, berdiri maupun berjalan pada bidang garis horizontal, vertikal maupun garis lurus.

Kata kunci: skill motorik dan fisik,manusia berkualitas.

Tanggung jawab untuk menjadikan manusia yang berkualitas merupakan tugas yang tidak dapat dielakkan oleh beberapa pihak, baik orang tua, guru maupun para pembina olahraga. Upaya menjadikan sosok manusia yang berkualitas secara seutuhnya baik dari sisi fisik maupun skill motorik perlu pembentukan dan pengamatan sedini mungkin. Hal ini untuk menghindari keterbentukan sikap maupun bentuk-bentuk anatomis tubuh yang salah sehingga berdampak pada asimetris tubuh yang selanjutnya berpengaruh pada penampilan.

Pengamatan skill motorik meliputi unsur-unsur gerak maupun pola gerak, sedangkan aspek fisik meliputi kondisi, bentuk dan sikap tubuh. Pengamatan- 
pengamatan semacam ini yang dilakukan seawal mungkin dan dilakukan secara berkala diharapkan dapat menemukan ketidaknormalan yang terjadi, selanjutnya dapat segera diatasi dan dikoreksi. Kebiasaan dan sikap tubuh yang salah menyebabkan adanya gangguan maupun efisiensi dalam lintas gerak tubuh. Pengamatan skill motorik dan fisik merupakan dua aspek yang sangat erat hubungannya, skill motorik sangat bergantung dari aspek fisik dan fisik yang salah akan menurunkan kualitas skill motoriknya. Demikian pentingnya pengamatan skill motorik dan fisik dalam upaya menjadikan manusia yang berkualitas, hanya yang menjadi petmasalahan sekarang adalah bagaimanakah cara pengamatan kedua aspek tersebut.

\section{PEMBAHASAN \\ Pengamatan Skill Motorik}

Pengembangan skill motorik merupakan aspek penting dalam peningkatan kualitas gerak. Pengembangan skill motorik meliputi penginderaan, kreasi gerak, improvisasi gerak dan koordinasi gerak. Menurut Sukarman (1988: 71) pada anak sampai usia sembilan tahun merupakan masa pembentukan pola gerak dasar (building the foundation). Pola semacam ini apabila terdapat kesalahan yang bersifat menetap dalam arti sudah menjadi kebiasaan, kebiasaan tersebut akan sangat sulit untuk diubah dan sangat membutuhkan waktu lama. Menurut Hurlock (1978: 151) perkembangan skillmotorik seseorang terjadi sesuai dengan urutan tertentu dari gerakan yang paling sederhana sampai pada gerak yang sangat kompleks, dari gerakan patah-patah dan kaku sampai pada gerakan koordinatif. Perkembangan semacam ini bergantung pada kematangan sistem saraf dan otot, perkembangan skill motorik mengikuti hukum arah perkembangan (Panggung Sutapa (1999: 57 ). Untuk anak yang normal pola pengendalian otot dan laju perkembangan dapat diramalkan karena pada umumnya mempunyai pola urutan yang sama hanya kecepatan dalam menuju tiap-tiap fase tidak sama. Pate (1980: 61) membagi perkembangan menjadi enam fase adalah:

1) Gerak reflektif. Banyak gerak refleks yang dilakukan pada masa bayi sebagai aksi adanya rangsang yang tidak disadari (memegang, menelan, menendang)

2) Integrasi rasa. Pada masa anak pengendalian jumlah otot jauh lebih banyak sehingga akan menghambat aksi refleks dan pada masa ini anak mulai belajar untuk memberi jawaban yang tepat terhadap rangsangan sensoris, sudah mulai 
belajar untuk memenuhi keinginannya dan berupaya mencoba berkali-kali sampai mendapatkan keinginan tersebut.

3) Pembentukan pola dasar gerak. Kematangan sistem saraf dan otot sangat berpengaruh pada penguasaan gerak, gerakan yang tadinya patah-patah, terisolasi akan menjadi teratur dan mengandung maksud. Proses pematangan selanjutnya, bergantung pada belajar dan pengalaman.

4) Penghalusan ketrampilan. Kemampuan saraf dalam mengendalikan otot sangat menentukan ketrampilan gerak, pada masa ini akan terbentuk pola gerak locomotor, non locomotor maupun yang manipulatif.

5) Penampilan. Pengembangan skill motorik sudah sampai pada puncak spesialisasi dan puncak prestasi.

6) Kemunduran. Terjadinya proses penuaan yang diikuti dengan perubahan anatomis baik tentang otak, jantung, paru, ginjal, otot, dan tulang menyebabkan terjadinya proses penurunan kapasistas kerja.

Perkembangan motorik merupakan perpaduan antara unsur kematangan dan pengendalian gerak tubuh yang kedua-duanya sangat bergantung pada kematangan sistem saraf dan otot. Banyak faktor yang berpengaruh terhadap perkembangan motorik antara lain : genetik, gizi, masa pralahir, peran dan pola orang tua asuh, kesehatan, dan jenis kelamin. Menurut Soegeng Santoso (2002 : 8) perkembangan motorik dan perkembangan kognitif secara konstan selalu berinteraksi. Proses interaksi semacam ini sangat tampak seperti pada teori pieget bahwa tahapan anak, dalam perkembangannya selalu melewati fase sensomotorik, praoperasional, konkret operasional, dan formal operasional walaupun kecepatan dalam melewati tiap fase dan lama dalam tiap fase dapat berbeda. Perkembangan motorik dan perkembangan kognitif terjadi melalui proses adaptasi untuk menyesuaikan terhadap lingkungan baik secara asimilasi maupun akomodasi. Asimilasi merupakan suatu proses menafsirkan pengalaman barunya sedangkan aspek akomodasi merupakan proses penyelesaian adaptasi dengan pengalaman baru tersebut. Proses akomodasi sangat penting dalam menguatkan ingatan karena pada masa ini berjalan dari mengenali, merasakan yang selanjutnya memodifikasi dan membuat keputusan. Asisimilasi dan akomodasi berjalan beriringan dan akan menjadi dasar dalam pengembangannya.

Tanda adanya perkembangan yaitu adanya perubahan baik perubahan anatomis, fisiologis maupun perilaku, anatomi ditunjukkan adanya perubahan kuantitas pada struktur tulang terutama pada tulang-tulang panjang yang 
selanjutnya akan berpengaruh pada proporsi tinggi dan berat badan. Perkembangan sisi lain ditandai dengan adanya perubahan kualitatif fungsional tubuh sehingga akan bekerja secara efektif dan efisien. Perubahan-perubahan semacam ini meliputi sistem kerja saraf otot, kardio respirasi maupun kardio vascular, sedangkan perlaku motorik memerlukan koordinasi dari beberapa komponen: saraf otot, sikap, dan kognitif. Menurut Sumarmo dkk (1982: 34) terlaksananya kegiatan motorik pada manusia karena adanya sistem otot yang melekat pada tulang dan saraf-saraf yang menginervasinya. Secara fisiologi komponen-komponen yang bekerja sama tersebut meliputi:

\section{Gerakan dan energi}

Dasar gerak dan energi adalah kontraksi dan relaksasi otot, dalam keadaan fisiologis otot berelaksasi dan berkontraksi apabila mendapat rangsangan dari susunan saraf baik motorik maupun sensoris. Saraf sensoris berpusat pada kornu anterior atau kornu motoris subtansia grisea medulla spinalis. Kerusakan saraf motoris perifer menyebabkan kelumpuhan yang lemah(flaksid yang merendahnya tonus otot (hipotoni), merendahnya reflek otot (hiporefleksi), dan atropi, sedangkan kerusakan pada motoris sentral menyebabkan kelumpuhan yang bersifat kaku, otot menjadi hipertonis, dan refleks otot meninggi.

Saraf sensoris dapat dibagi menjadi tiga golongan: (1) perasaan kulit yang dapat menyebabkan adanya perasaau nyeri paha dan siku. (2) perasaan sendi otot dan tendo menyebabkan dapat mengetahui bagian dari tubuh jika sedang bergerak, arah pergerakan dan sikap gerak, dan (3) perasaan visera yaitu adanya perasaan bagian dalam tubuh hangat, dingin, dan nyeri dalam.

\section{Koordinasi}

Untuk dapat melalukan gerakan yang kompleks penuh dengan koordinatif dari sejumlah otot atau beberapa kelompok otot maka harus diatur sedemikian rupa oleh sistem saraf dalam serebelum. Untuk terlaksana koordinasi yang baik, serebelum terlebih dahulu menerima rangsang dari otot yang kemudian diolah di dalam serebelum yang kemudian disampaikan kembali ke otot untuk melakukan gerakan. 


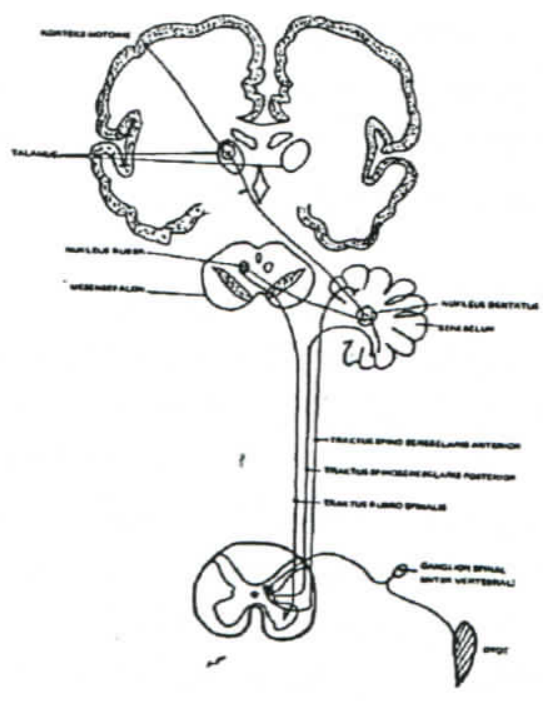

\section{Keterangan :}

Koordinasi gerak diatur mulai dari alur otot ke serebelum dan dikembalikan ke otot setelah diolah di dalam serebelum.

\section{Refleks}

Refleks merupakan jawaban adanya rangsang yang di luar kehendak sehingga yang bersangkutan menyadari adanya gerakan setelah terjadi. Rangsang refleks disalurkan melalui saraf perifer eferen dan rangsang responnya melalui saraf perifer aferen.

\section{Tonus}

Tonus otot diatur oleh spindee otot yang berada di dalam jaringan otot. Aktivitas otot akan diatur pula oleh traktur piramidalis yaitu berfungsi dalam menghambat tonus otot agar tidak berlebihan yaitu terjadinya kekauan otot.

Evaluasi perkembangan motorik merupakan suatu cara menemukan pencapaian proses pembelajaran sehingga dapat mengukur tingkat keberhasilan proses pembinaan dalam pengembangan motorik yang diberikan oleh orang tua atau guru. Keberhasilan perkembangan skill motorik dari hasil belajar akan terlekat dari grafik setiap tugas dalam satu bulanan. Hasil proses belajar yang 
benar akan menunjukkan garis menanjak pada nilai keberhasilan dalam melakukan aktivitas, sedangkan garis menurun menunjukkan adanya kegagalan. Jumlah keberhasilan akan meningkat setiap kali anak melakukan latihan atau jumlah kesalahan yang dilakukan akan berkurang.

Adapun prinsip-prinsip dasar evaluasi perlu memperhatian hal-hal:

1. Menyeluruh, artinya tidak dilakukan secara terpisah dengan proses pembelajaran, mengingat evaluasi tersebut lebih banyak menilai proses perilaku anak dan hasil perbuatán anak yang pada umumnya tidak dapat dilakukan dengan tes tertulis (peper and pencil test);

2. Berkesinambungan, artinya dilakukan secara terencana, bertahap, dan terusmenerus. Hal ini dilakukan agar informasi yang diperoleh betul-betul berasal dari gambaran perkembangan proses pembelajaran motorik pada anak;

3. Berorientasi pada tujuan, artinya dalam menetapkan indikator harus menggunakan acuan standar, guru, orang tua, atau pembina dapat menilai hasil kegiatan anak melalui indikator yang terwujud dalam meningkatkan hasil pertumbuhan dan perkembangan;

4. Objektif, artinya penilaian dilakukan sesuai dengan kriteria yang telah ditetapkan. Prasangka, keinginan, dan perasaan tertentu tidak boleh mempengaruhi penilaian yang dilakukan.

5. Mendidik, artinya penilaian yang dapat digunakan untuk membina dan memberikan dorongan kepada semua anak dalam meningkatkan hasil pertumbuhan dan perkembangan;

6. Kebermaknaan, artinya hasil penilaian harus memiliki arti, baik bagi orang tua, guru, pembina, anak itu sendiri, maupun pihak lain yang memerlukannya.

\section{Pengaturan Fungsi Motorik Sebagai Reaksi Terhadap Rangsang}

Perkembangan keterampilan pada anak memerlukan waktu lama untuk dapat mencapai arah penampilan yang sempurna. Perkembangan semacam ini berlangsung sejak lahir, hal ini akan berlangsung dengan baik hanya oleh karena adanya integrasi rasa sensorik dan motorik yang dikendalikan oleh sistem saraf. Sebagian terbesar fungsi tubuh diatur oleh sistem saraf yang bersifat khas dalam hal pengatur kontraksi otot. Kegiatan sistem saraf berasal dari pengalaman sensorik baik berupa reseptor visual, auditorius maupun reseptor raba di 
permukaan tubuh. Kegiatan semacam ini secara bersama-sama disebut fungsi motorik dari sistem saraf dan otot. Otot rangka dalam tubuh dapat diatur dari berbagai tingkat sistem saraf. Secara khusus dalam mengatur gerakan tubuh terutama dalam memberikan atau jawaban dari adanya rangsang.

Sususan saraf terdiri atas dua bagaian yaitu, saraf sentral dan perifer. Saraf sentral terdiri atas serebrum dan serebelum sedangkan untuk perifer terdiri atas saraf somotik dan saraf autononom (simpatis dan para simpatis). Saraf sentral merupakan komputer yang menjadi pusat pengendali kegiatan mental dan mengatur fungsi alat-alat tubuh. Pada manusia pergerakan motorik dimungkinkan karena adanya sistem otot yang melekat pada tulang dan sarafsaraf yang menginervasinya. Menurut Sumarmo dkk (1982: 34) terlaksanaanya kegiatan motorik yang sempurna akibat adanya komponen-komponen yang bekerja sama. Komponen tersebut meliputi gerakan dan energi, koordinasi, keseimbangan refleks, tonus otot dan asosiasi. Menurut Soejanto (1987: 86) fungsi utama saraf menerima rangsang, mengirim rangsang dari satu tempat ke tempat lain dan selanjutnya mengadakan reaksi sebagai jawaban atas rangsang tersebut. Menurut Guyton (1981: 92) gerakan motorik atas rangka dapat diatur dari berbagai tingkatan di dalam sistem saraf pusat yang meliputi: (a) medulla spinalis; (b)subtansi retikularis medulla oblongata pons dan mesensefalon; (c) ganglia basalis; (d) serebelum, dan (e) korteks motorik. Tiap-tiap tingkatan mempunyai peran khusus dalam mengatur gerakan motorik, tingkatan yang lebih rendah terutama penting untuk gerakan refleks terhadap jawaban rangsang sedangkan pada tingkatan yang lebih tinggi terutama untuk gerakan yang sengaja diatur dalam proses berpikir.

\section{Fungsi Tingkat Sistem Saraf:}

1. Medula Spinalis: Informasi sensorik diintegrasikan pada semua tingkatan sistem saraf dan menyebabkan reaksi medula spinalis dengan refleks yang paling relatif sederhana, diperluas di dalam batang otak dengan reaksi yang lebih rumit dan akhirnya diperluas di serebrum tempat reaksi paling rumit dikendalikan. Medula spinalis dimulai dibagian bawah dari medulla oblongata setinggi korpus vertablis servikalis dan memanjang hingga karpus vertebralis lumbalis. Medulla spinalis halnya otak berada dalam saku araknoidea yang bersisi cairan otak dan saku araknoidea berakhir didalam kanalis vertebralis dalam tulang sakum. Medulla spinalis bagian servikal keluar 8 pasang saraf 
spinal torakal 12 pasang lumbal 5 pasang sakral 5 pasang dan bagian koksigial 2 (dua) atau 3 (tiga) pasang (sumarmo markam dkk. 1982 : 17)

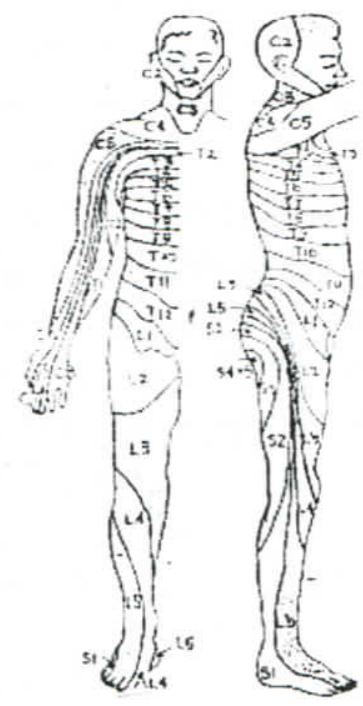

Keterangan:

Tiap neuron mensarafi dermaton, mioton dan asteotan yang sesuai.

Substansi grisea medulla spinalis merupakan daerah integratif untuk refleks medulla spinalis dan fungsi motorik lainnya. Otot dan tendo mempunyai banyak reseptor, namun dua reseptor jenis khusus sangat berperan dalam mengkoordinasikan gerakan otot jenis tersebut, yaitu muscle spindle dan organ tendo golgi. Muscle spindle berperan dalam mengatur perubahan panjang serabut otot dan kecepatan perubahan panjang tersebut, sedangkan organ tendo golgi mempunyai fungsi mendeteksi ketegangan tendo otot selama kontraksi. Untuk anak-anak di bawah umur lima tahun koordinasi dua reseptor yaitu muscle spindle dan organ tendo golgi belum begitu baik sehingga gerakan motorik pada diri anak pada awal masih kelihatan kasar (Pangggung Sutapa, 1999: 55).

2. Subtansi Retikularis Medulla Oblongata Pons dan Mesensefalon.

Batang otak Trunkus serebri terdiri atas: (a) diensefalon (b) mensefalon (c) pons, dan (d) medulla oblongata. Diensefalon ke atas berhubungan dengan serebrum dan medulla oblongata ke bawah menjadi medulla spinalis. Batang otak merupakan perluasan yang kompleks dari medulla spinalis yang terdapat banyak sirkuit 
neuron untuk mengatur keseimbangan dan membantu tubuh melawan grafitasi.

Keterangan gambar:

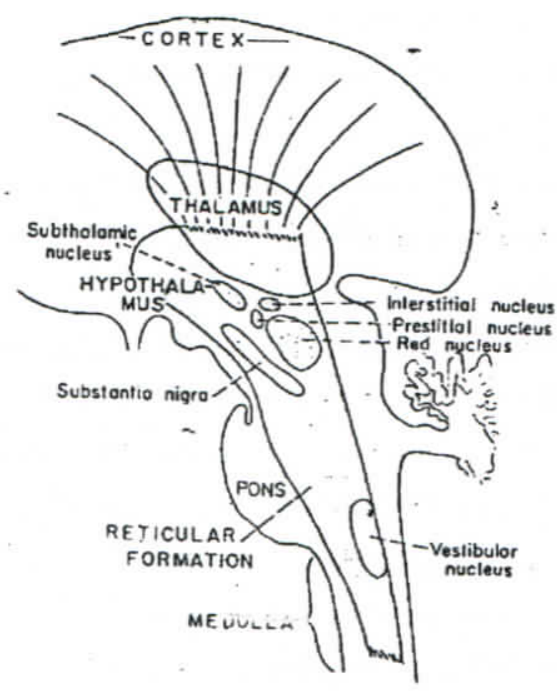

Di dalam batang otak terutama didalam medulla oblongata pons, mensenfalon dan diensefalon terdapat neuron-neuron yang disebut formasio retikularis yang menghubungkan bagian atas dengan thalamus, hipotalamus, dan bagian bawah dengan inter neuron medulla spinalis.

\section{Ganglia Basal}

Ganglia basal merupakan kumpulan badan-badan sel saraf di dalam diensefalon dan mensenfalon. Ganglia terdiri atas nucleus caudatus, putanen, globus palidus nucleus subtalamiklus, nukleus latteralis thalamus, sentrum medianum talamus, nucleus puber dan substansia nigra. Fungsi motorik ganglia basal yaitu untuk micnghambat tonus otot-otot, menentukan sikap dan gerakan dasar yang terjadi otomatis. Kerusakan pada ganglia basal khususnya pada globus palidus dan subtansia nigra menimbulkan kekakuan otot fleksor dan ektensar yang secara serentak timbul regiditas dan dapat pula mnimbulkan tremor yang kasar pada tangan dan kepala, sedangkan kerusakan pada nucleus subtalamikus menimbulkan gejala hemibalisme yaitu gerakan melempar dan memutar mutar lengan, menendang, memutar-mutar tungkai. Kerusakan pada nucleus kaudatus, putamen menimbulkan gerakan spontan abnormal yang sering disebut atetasia 


\section{Pengamatan Fisik.}

Penilaian seseorang tentang sosok manusia yang berkualitas banyak macam vairasi dan indikatornya, namun demikian secara umum dikatakan memiliki sosok yang berkualitas dapat dilihat dari sisi: intelektual, tingkah laku, skill motorik, maupun fisiknya.

Bentuk dan sikap tubuh merupakan bagian dari aspek fisik, sedangkan bentuk dan sikap tubuh sangat ditentukan oleh otot dan tulang. Menurut Astrand (1986: 273) tulang merupakan salah satu jaringan terbesar di dalam tubuh yang secara umum berfungsi sebagai alat untuk bergerak, tempat melekatnya otot, melindungi organ-organ tubuh yang lunak, sebagai pembentuk sistem tuas selama berkontraksi serta sebagai pembentuk tubuh di samping lemak. Brooks (1976: 666) menyatakan tinggi rendahnya badan sangat ditentukan oleh rangka (skelet) terutama pada tulang-tulang panjang (tungkai). Tulang terdiri atas matrik keras yang diperkuat oleh endapan-endapan garam kalsium. Rata-rata kompakta mengandung matriks sekitas 30 persen dan 70 persennya merupakan medium homogen yang dinamakan zat dasar. Zat ini terdiri otot cairan ekstra zat ditambah mikroprotein yang mengadung kondriotin sulfat dan asam hiakronat yang berfungsi memberikan medium untuk pengendapan garam-garam kalsium. Menurut Sunarko (1988: 5) pengamatan fisik yang dilakukan secara rutin pada masa pertumbuhan sangat diperlukan sebab dengan mengetahui bentuk dan sikap tubuh yang abnormal lebih dini, kelainan tersebut akan lebih mudain diatasi dan di koreksi. Kebiasaan sikap, posisi yang salah dan berlangsung lama dapat menyebabkan keterbentukan sikap dan bentuk tubuh yang salah sehingga akan berdampak pada tidak efesiennya dalam sistem gerak tubuh. Ketidakefisiennya ini baik dilihat dari waktu yang dibutuhkan dalam gerak mupun sistem energinya, di samping ketidakefisiennya dalam sistem gerak secara estetika juga akan terganggu.

Pengamatan bentuk dan sikap tubuh pada masa pertumbuhan dapat dilakukan pada posisi dudk, pada saat sedang beraktivitas, maupun pada posisi berdiri. Pengamatan pada posisi duduk tersebut dapat mengetahui ada tidaknya keserasian antara kepala dalam garis lurus, bahu dalam garis horizontal demikian pula pada posisi berdiri dapat mengamati dari kepala sampai telapak kaki. Pengamatan ini terutama ditujukkan pada kelainan susunan ruas-ruas tulang belakang. Pengamatan semacam ini dapat dilakukan dari belakang maupun samping. 


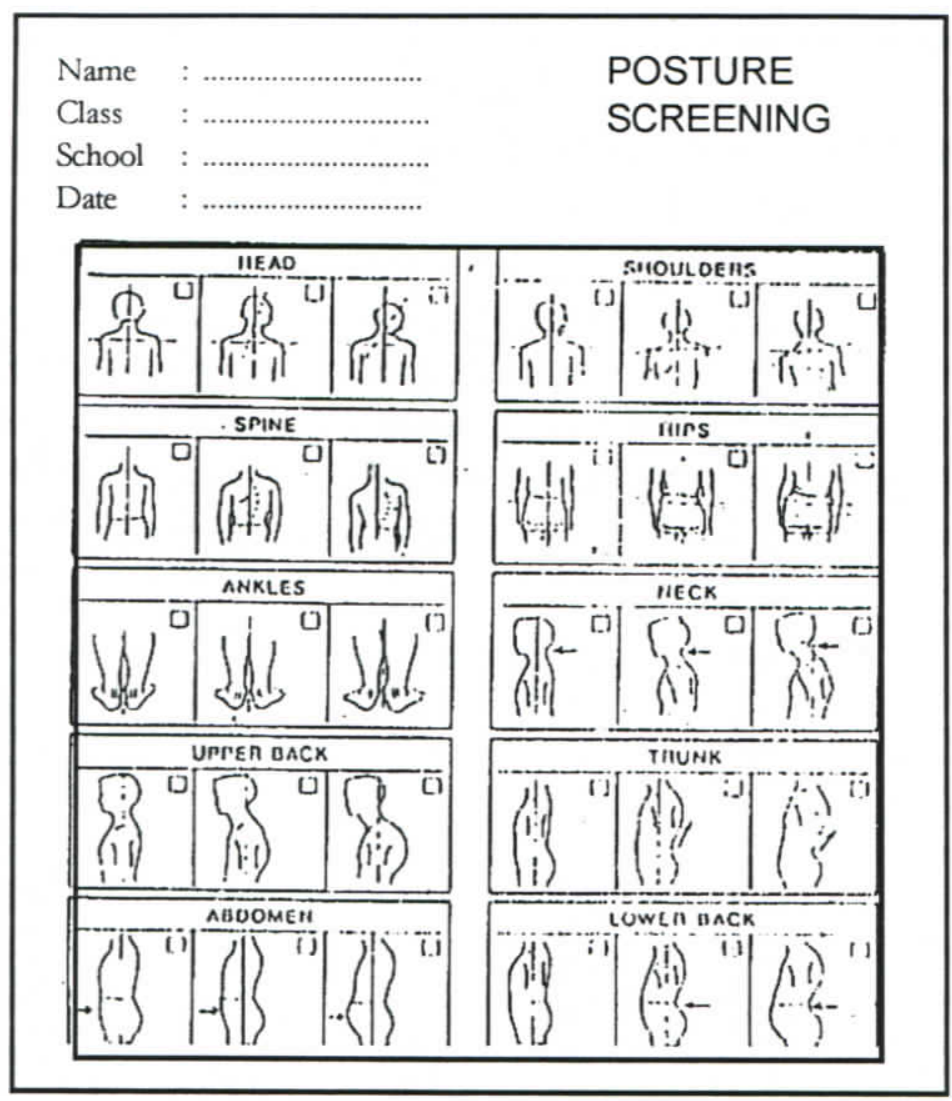

Keterangan:

Pengamatan postur tubuh dengan posisi berdiri badan menempel pada dinding - dengan garis vertikal maupun horisontal. 
Kelainan-kelainan pada ruas tulang belakang (biperlardosis, kiposisi, dan sklaiosis) posisi kedua kakai ("O" atau " $\mathrm{X}$ ") tinggi pundak kanan dan kiri serta posisi kedua telapak kaki "Varus dan Valgus".
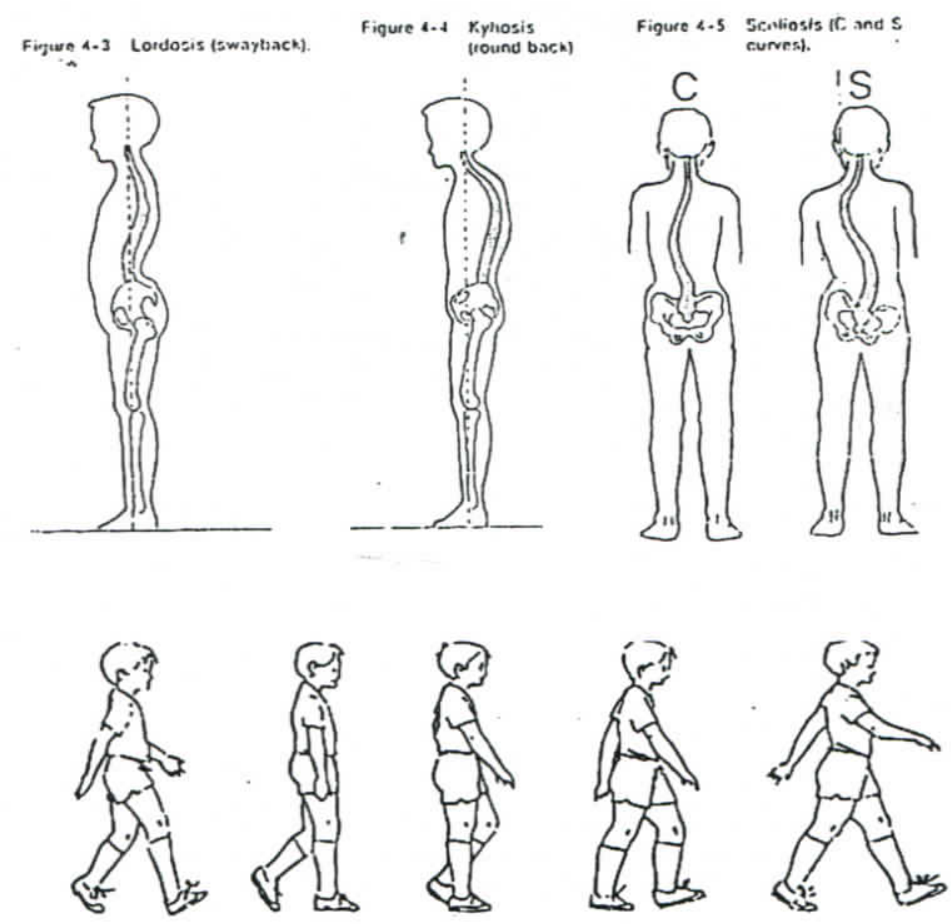

Keterangan:

Pengamatan posisi kaki maupun telapan kaki akan lebih mudah berjalan dalam satu garis lurus.

Ketidakadanya gangyuan dalam beraktivitas akibat dari keabnormalan fisik memungkinkan pengembangan pembentukan pola gerak dasar terutama pada masa pertumbuhan. Hal ini sangat penting terutama dalam mendapatkan sumber daya manusia yang berkualitas, untuk membentuk menusia pembangun serta menyiapkan pembinaan pembibitan calon olahragawan yang tangguh di masa mendatang. Di samping itu, dengan terbentuknya sikap dan bentuk tubuh yang baik memungkinkan dalam pengembangan pola gerak motorik (locomotor, non locomotor, dan monipulatif) lebih akan menampakkan hasil yang menggembirakan. 


\section{KESIMPULAN}

Skill motorik dan fisik yang terbentuk akan bersifat menetap, kesalahan yang terbentuk akan terpola dan sulit untuk dirubah serta membutuhkan waktu lama. Pengamatan skillmotorik dan fisik dapat dilakukan dengan berbagai macam cara, pengamatan yang dilakukan secara berkala akan memungkinkan menemukan kesalahan atau ketidaknormalan seawal mungkin.

Skillmotorik dan fisik yang salah (abnormal) menyebabkan kurang estetis dan menyebabkan inefisiensinya dalam sistem gerak tubuh sehingga energi yang diperlukan lebih banyak dan waktu pelaksanaan lebih lama. 


\section{DAFTAR PUSTAKA}

Astrand, P.O, Rodhal, K. (1986). Textbook of Work Physiology: Pbisyological Bases Of Exercise (3rd . ed). New York: Mc. Grow Hill Book CO

Brooks, G.A., Fahey, T.D. (1977), Exercise Pbysiology Human Bio Energetic and Its Aplication. New York: John Willay \& Sons.

Guyton, A. C. (1981). Text Book Of Physiology. Phyladelphia: WB Sounders Company Hurlock, E.B. (1970). Child. Growth and Development. New York: Mc. Grow Hill Book Company. St.

Panggung Sutapa (1999) "Sistem saraf otot dan pengaruhnya pada perkembangan motorik anak". Majora: Vol. 5 No. 3 Yogyakarta

Pate, R.R. Mc. Clenaghan, B, Rotella, R. (1984). Scientific Foundation of Coacbing. Philadelpia: Sauders College Publishing

Soegeng Santoso dkk (2002) Model pengembangan motorik anak prasekolah. Jakarta: Depdiknas.

Soekarman, 1988, "Masalah olahraga pada anak". Makalab Surabaya.

Sunarko Setyawan, 1988, "Pengamatan Pola Gerak Dasar pada Anak". Makalab Airiangga Surabaya.

Sumarmo Markam dkk (1982) Neuro - Anatomi. Jakarta: Indira 